\title{
Gleanings from the Canadian Journal of Forest Research
}

On the assumption that the material presented in the June Chronicle on points of interest to the non-researcher in the first issue of the above journal was of use to someone, I have done the same for the second issue. At any rate, no author has sued yet for loss of reputation.

Various types and rates of nitrogen fertilizers were applied by Carrier and Bernier to the soil of a 38-year-old stand of jack pine, originating from a fire, located northwest of Chicoutimi in Quebec. The soil was a medium to coarse sand with gravel. From analyses of the percentages of nitrogen lost as ammonia and of the effects of precipitation, the authors suggest that the use of a slow solubility fertilizer - sulfur coated urea was considered a good form - had advantages.

Studies by Lavallée and Bard on 35- to 55year-old artificially-wounded sugar maple and yellow birch confirmed reports on naturallywounded trees that the discoloration process was more rapid in yellow birch than sugar maple. This difference, however, was only evident after 3 years, although the progression radially was distinct after 8 months and was accentuated with time. Bacteria colonized wood of yellow birch in greater numbers and more rapidly than that of sugar maple but, on the whole, decay fungi did not vary much between the two. The process of discoloration and decay following wounding was a gradual one requiring the action of a succession of various organisms.

Cambial activity in seedlings of the provenance of Douglas-fir examined by Worral was controlled by the buds and shoots (terminal or adventitious). There was no internally imposed rest period of the cambium. In 35-year-old Douglas-fir, Dobbs and Scott found that the greatest daily fluctuations in stem circumference occurred in the mid-crown region of the stem. They suggest that the shrinkage and swelling occurs in the peripheral tissues of the stem in response to lateral transfer of water to and from the xylem.

Two different studies are reported on rooting cuttings. Brix and Barker stimulated rooting of mature, hard-to-root Douglas-fir cuttings by grafting them at the base to cuttings from seedlings of the same species. Stimulation originated from the new roots, not from the tops, of the seedling cuttings. Rauter mentions advantages of using plastic tubes for rooting cuttings. Although rooting ability varied from tree to tree within the species and hybrids of spruce tested, high rooting percentages were obtained which could lead to mass propagation of superior material.

Two other papers are included in this second issue of the journal. Analyses of latewood density in Engelmann spruce, using x-ray techniques, and ring width were useful for dating purposes according to Parker and Enoch. Purposes of the study were evaluation of Engelmann spruce at Peyto Lake in Alberta for dendrochronological quality characteristics, comparison of tree-ring record with environmental data, and construction of master tree-ring chronology for dating wood specimens from the recessional area of Peyto glacier. The remaining paper by Jeglum and others is concerned with analysis of vegetation-environment data where the skills of a mathematician and the ecologists's knowledge of material are required in the detection of ecological relationships.

D. C. F. Fayle

\section{Meetings}

\section{CIF meeting}

The 64th Annual Meeting of the Canadian Institute of Forestry will be held the last week in August of 1972 at the University of New Brunswick, Fredericton, N.B. The Annual Meeting Committee will be supplying details later in the year. Plan to spend at least part of your 1972 vacation in New Brunswick and attend the Annual Meeting of the Institute.

\section{6th TAPPI forest biology conference}

The sixth TAPPI Forest Biology Conference will be held May 1-3, 1972 at the Institute of Paper Chemistry, Appleton Wisconsin. Three symposia and sessions of contributed papers have been scheduled under the Conference theme, "Innovative approaches to increase fiber yield and pulp production". Individuals who would like to contribute papers should contact the Program Chairman, Dr. Philip R. Larson, North Central Forest Experiment Station, Rhinelander, Wisconsin. 54501.

\section{Salon de l'avenir}

Salon de l'avenir/Projection into the future is designed to encourage public interest in the fight undertaken by government and industry against pollution and introduce promising new career opportunities in the fields of environmental control. The Salon will be held at Place Bonaventure in Montreal, November 3-7, 1971. 